\title{
The Prolo Scale: history, evolution and psychometric properties
}

\author{
Carla Vanti · Donatella Prosperi $\cdot$ Marco Boschi
}

Received: 20 October 2012/ Accepted: 15 April 2013/Published online: 10 May 2013

(c) The Author(s) 2013. This article is published with open access at Springerlink.com

\begin{abstract}
Background The Prolo Scale (PS) is a widely accepted assessment tool for lumbar spinal surgery results. Nevertheless, in the literature there is a dearth of consensus about its application, interpretation and accuracy. The purpose of this review is to investigate the evolution of the PS from its introduction in 1986 to the present, including an analysis of different versions of the scale and research on the existing studies investigating its psychometric properties.

Materials and methods PubMed, Cochrane Library and PEDro databases were searched. Studies in English, Italian, French, Spanish and German published from 1986 to December 2012 were analyzed.

Results The original lumbar surgery outcome scale consisted of two Likert-type scales (economic and functional). There are three more versions of the scale: Schnee proposed one consisting of 10 items, Brantigan made one with 20 items and introduced 2 more subscales (pain and medication), and Davis adapted the scale for the cervical spine. PS is often mentioned without any specific reference to the version used; therefore, a homogeneous comparison of
\end{abstract}

\author{
C. Vanti · M. Boschi \\ University of Bologna, Bologna, Italy \\ C. Vanti - D. Prosperi \\ University of Padova, Padova, Italy \\ D. Prosperi \\ University of Trieste, Trieste, Italy \\ M. Boschi $(\bowtie)$ \\ Via Gramsci 19, 40012 Calderara di Reno, Bologna, Italy \\ e-mail: mrc.boschi@gmail.com \\ M. Boschi \\ University of Genova, Genova, Italy
}

studies is difficult to achieve. Several authors agree on the need to embrace a multidimensional measuring system to evaluate low back pain (LBP), but there is still no consensus regarding the most reliable tool. To date, PS has been mostly used as secondary outcome measure in association with validated primary measures for LBP.

Conclusions The Prolo Scale has been adopted for clinical examination for 20 years because it is easy to administer and useful to compare significant amounts of data from surgical studies carried out at different times. Although several authors demonstrated the scale sensitivity among a battery of tests, no thorough validation study was found in the current literature.

Keywords Outcome assessment · Questionnaires · Orthopedic surgery - Spinal fusion · Low back pain

\section{Introduction}

Current literature stresses the relevance of adopting outcome measures to assess the effectiveness of conservative or surgical treatments. Among different evaluation tools, questionnaires are widely employed for their simplicity, reproducibility and acceptability.

The patients' opinion about treatment results is recognized as a relevant part of the assessment of surgical procedures. In 1986, Donald J. Prolo and colleagues [1] developed the Prolo Scale (PS), with the aim to introduce a widely accepted tool to evaluate the results of lumbar spine surgery.

This scale is easy to administer, semi-quantitative and independent from the surgical technique. It provides an index of surgical efficacy and is useful to compare studies carried out at different times and on heterogeneous patient 
populations. To date, this scale has been used either as a primary outcome or in association with other outcome scales, and it is known as the Prolo Scale, Prolo score, Prolo Economic Functional Rating Scale, anatomic economic functional grading system or other "modified" Prolo Scale.

Several modifications concerning the name and structure of this scale (e.g., item type, item number, anatomical district of interest) were observed in the literature. Moreover, the cutoff for clinical success was commonly rated as excellent, good, fair or poor, but some specifications for each item according to the criteria of Odom [2] and Mac$\mathrm{Nab}$ [3] were recognized. Although several authors employed the PS, no literature review analyzed the characteristics and accuracy of this questionnaire.

This study aimed at investigating the evolution of the PS from its introduction to the present, including the analysis of different versions of the scale, the assessment of its psychometric properties and research on non-English validated versions.

\section{Materials and methods}

The research was carried out by consulting the PubMed, Cochrane Library and PEDro databases.

This research strategy was applied: (Prolo score OR Prolo Scale) AND (outcome assessment OR outcome measure OR clinical success) AND (lumbar surgery OR lumbar fusion OR spinal surgery).

Further research was performed using the following keywords: valid* outcome assessment, economic and functional outcome, low back pain (LBP), sciatica, disc herniation, spondylolisthesis and stenosis.

We collected only studies on humans in English, Italian, French, Spanish or German and published from 1986 to December 2012.

Two independent researchers $(\mathrm{CV}, \mathrm{DP})$ identified and selected the studies and processed data with the same method. A third reviewer (MB) was consulted in case of disagreement.

Results were organized into different sections: description, origin, diffusion, modified versions and psychometric properties.

\section{Results}

Initially, 126 studies were identified. Afterward, 33 were excluded because they did not match the inclusion criteria, 16 were excluded because no full text was available, and 13 were excluded because they did not mention the adopted version. Hence, the review was conducted on 64 studies
(Fig. 1), out of which 7 not only administered the scale, but also analyzed it and considered the factors that influenced its accuracy (Table 1).

\section{Description of the Prolo Scale}

The original scale is bidimensional. It is divided into an economic subscale (E) and a functional one $(\mathrm{F})$, which present respectively the level of bearable work for the patient and the role pain plays in daily life. It consists of two 5-point Likert-type scales, where 1 is the worst condition and 5 is the best (Table 2).

The total score $(\mathrm{ExFx})$ is obtained by adding scores of each subscale, resulting in a minimum score of 2 to a maximum of 10 points, which can be rated as excellent (10-9), good (8-7), fair (6-5) and poor (4-2). In the original study, Donald J. Prolo administered the scale to 34 patients who underwent posterior lumbar interbody fusion surgery.

Collected data were expressed as the ratio between the pre-surgery and final scores at 1 -year follow-up. This ratio provided surgical outcome independent from surgical technique, and it was more objective than self-reported questionnaires (e.g., the Oswestry low back pain disability questionnaire-ODI) or anatomical examinations conducted by surgeons strictly related to the surgical success.

The origin of the Prolo Scale

The original PS had been modified with respect to the one already used by Dawson, Urist and Lotysch in a retrospective study [4] conducted in 1981 on a sample of 58 patients who underwent intertransverse process lumbar arthrodesis from 1973 to 1979.

Similarly, Dawson and colleagues referred to a tool that had already been adopted long before, called the Massachusetts General Hospital Anatomic Economic Functional Rating System, which included three five-item subscales: anatomic, economic and functional (AEF) (Table 3) $[5,6]$.

Conversely to Dawson's approach, Prolo and colleagues only considered items relative to economic and functional areas (EF), describing elsewhere the evaluation criteria of anatomical fusion, which was correlated with the scores obtained only by the surgeon. This choice could be explained by the small sample size or the authors' intention to create a scale that is easy to administer and independent from the surgical technique.

Moreover, Prolo decided to modify the scoring method from the AEF system, with a minimum of 0 (disability) to a maximum of 4 points, to the EF system, with a minimum value of 1 (disability) to a maximum of 5 points. 
Fig. 1 Flow chart

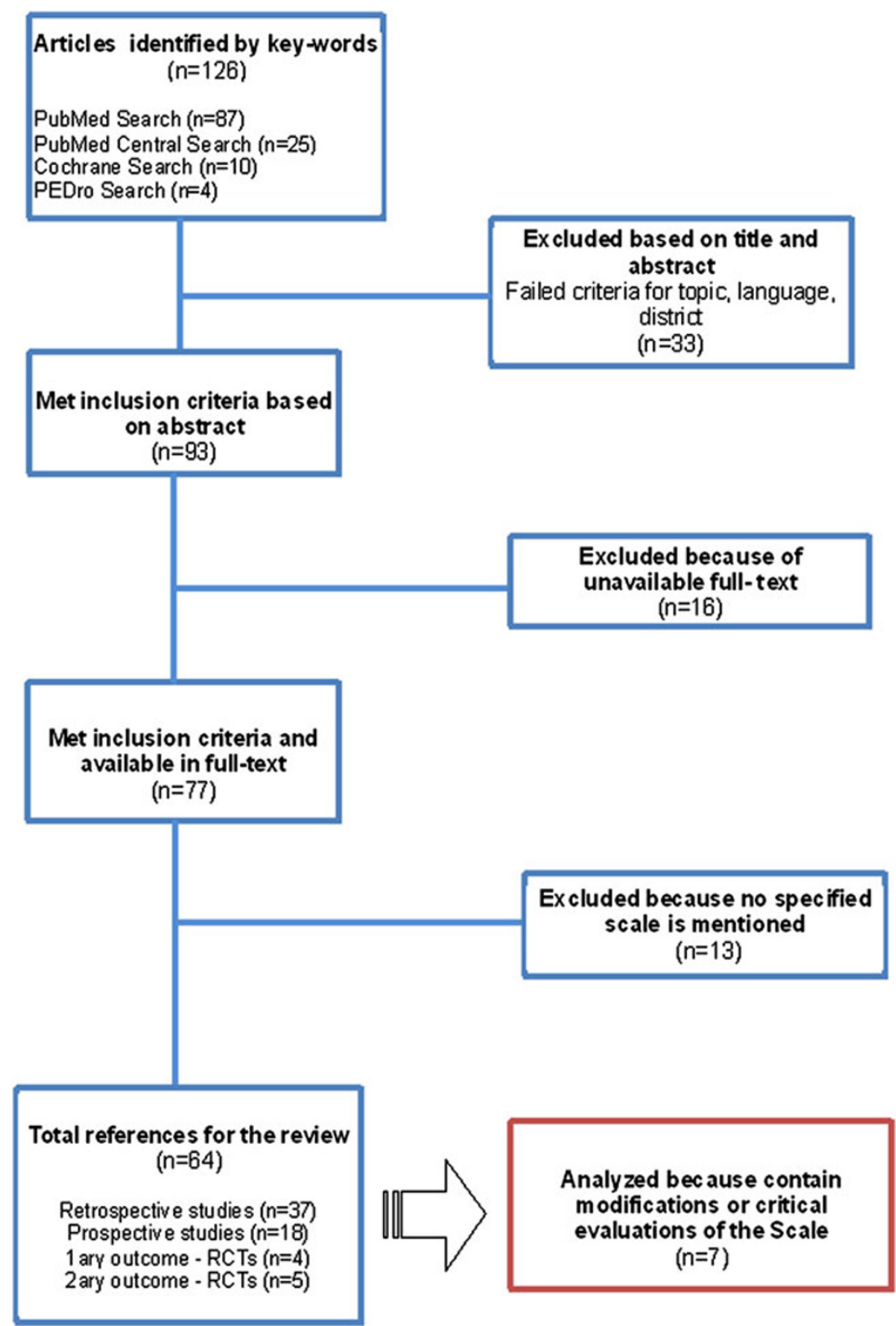

Diffusion of the Prolo Scale

Several researchers administered the original PS [7-34] as a main outcome or in association with other outcome measures, mostly in studies conducted on degenerative pathologies of the lumbar spine. Some authors used the PS by properly adapting items for the postoperative evaluation of function of other spinal districts, for example, the thoracic spine in case of fracture stabilization [35, 36] or discectomy [37] or the cervical spine.

In the early 1990s, some authors followed Prolo's intention of creating a widely accepted assessment tool by publishing retrospective studies conducted on a significant population sample.
In 1992, Pappas et al. [7] carried out a retrospective study in which they administered the functional economic outcome rating scale to patients who underwent surgery with three different surgical procedures for lumbar hernia. Pappas and colleagues stated that the scale was a simple and useful tool for standard evaluation of the efficacy of different surgical techniques in opposition to self-report measures. They proposed that in future studies both the surgeon and the patient have to fill out the scale in order to allow a comparison between the results of the two different assessments. A discrepancy was found with respect to the stratification of combined scores. In fact, Prolo and colleagues proposed four outcome categories, excellent (10-9), good (8-7), fair (6-5) and poor (4-2), while Pappas 
Table 1 Table of selected articles

\begin{tabular}{|c|c|c|c|c|}
\hline Article & $\begin{array}{l}\text { Type of } \\
\text { study }\end{array}$ & Patient sample/follow-up & Aim of study & Comments \\
\hline Berger [10] & Retrospective & $\begin{array}{l}\text { 1,000 workmen's } \\
\text { compensation patients/mean } \\
\text { follow-up } 51 \text { months }\end{array}$ & $\begin{array}{l}\text { Clinical outcome assessment } \\
\text { measured on independent } \\
\text { neurological and orthopedic } \\
\text { examination vs disability score } \\
(\mathrm{PS})^{\mathrm{a}}\end{array}$ & $\begin{array}{l}\text { Influence of psychosocial factors and } \\
\text { chronic pain. Sample selection bias? }\end{array}$ \\
\hline Blount [42] & Review & $\begin{array}{l}\text { Revision of } 27 \text { studies on } \\
\text { spinal fusion published from } \\
1990 \text { to } 2000\end{array}$ & $\begin{array}{l}\text { Reporting the most validated } \\
\text { outcome measures and proposing } \\
\text { a multi-dimensional set for spinal } \\
\text { fusion outcome }\end{array}$ & $\begin{array}{l}\text { Prolo economic score (Schnee) is } \\
\text { recommended for return-to-work } \\
\text { assessment. Prolo functional score is } \\
\text { not recommended for disability } \\
\text { assessment }\end{array}$ \\
\hline Brantigan [51] & Prospective & $\begin{array}{l}221 \text { patients treated with PLIF } \\
\text { and pedicle screw fixation } \\
\text { (I/F cage)/2 years follow-up }\end{array}$ & $\begin{array}{l}\text { Testing the safety and efficacy of } \\
\text { an interbody fusion device }\end{array}$ & $\begin{array}{l}\text { Different version of PS (20 items } \\
\text { instead of 10) }\end{array}$ \\
\hline Porchet [11] & Cohort Study & $\begin{array}{l}394 \text { consecutive patients with } \\
\text { sciatica/1 year follow-up }\end{array}$ & $\begin{array}{l}\text { Association between clinical } \\
\text { examination (PS, VAS } \\
\text { RMDQ }^{\mathrm{d}}, \mathrm{SF}-36^{\mathrm{e}} \text { ) and } \\
\text { radiological assessment (Modic) }\end{array}$ & $\begin{array}{l}\text { PS is used for assessment of } \mathrm{LBP}^{\mathrm{f}} \text { (not } \\
\text { for surgical outcome). }\end{array}$ \\
\hline Schnee [43] & Retrospective & $\begin{array}{l}52 \text { patients treated with PLIF } \\
\text { and pedicle screw fixation } \\
\text { for spondylolisthesis/mean } \\
\text { follow-up } 18.6 \text { months }\end{array}$ & $\begin{array}{l}\text { Efficacy of the technique measured } \\
\text { as fusion rate and variation of PS } \\
\text { scoring }\end{array}$ & $\begin{array}{l}\text { Different version of PS (adaptation for } \\
\text { patient) }\end{array}$ \\
\hline Voorhies [13] & Prospective & $\begin{array}{l}110 \text { patients operated for first } \\
\text { decompression of lumbar } \\
\text { root/mean follow-up } \\
12 \text { months }\end{array}$ & $\begin{array}{l}\text { Identifying tools and risk factors to } \\
\text { propose a predictive model of } \\
\text { clinical success ( } 6 \text { measures set) }\end{array}$ & $\begin{array}{l}\text { Analysis of prognostic factors and } \\
\text { psychometric properties of PS. } \\
\text { Statistical evidence of responsiveness } \\
\text { to change }\end{array}$ \\
\hline Woertgen [23] & Prospective & $\begin{array}{l}121 \text { lumbar herniated disc } \\
\text { patients/1 year follow-up }\end{array}$ & $\begin{array}{l}\text { Different predictive factors of } \\
\text { different scores }\left(\mathrm{LBOS}^{\mathrm{g}}, \mathrm{PS},\right. \\
\text { pain grading scale) }\end{array}$ & $\begin{array}{l}\text { Similar results on LBOS and PS, but no } \\
\text { statistical analysis of psychometric } \\
\text { properties }\end{array}$ \\
\hline
\end{tabular}

${ }^{a}$ Prolo Scale

${ }^{b}$ Posterior lumbar interbody fusion

c Visual analog scale

d Roland and Morris disability questionnaire

e Short-form 36

${ }^{\mathrm{f}}$ Low back pain

g Low back outcome score

Table 2 Economic and functional rating scale [1]

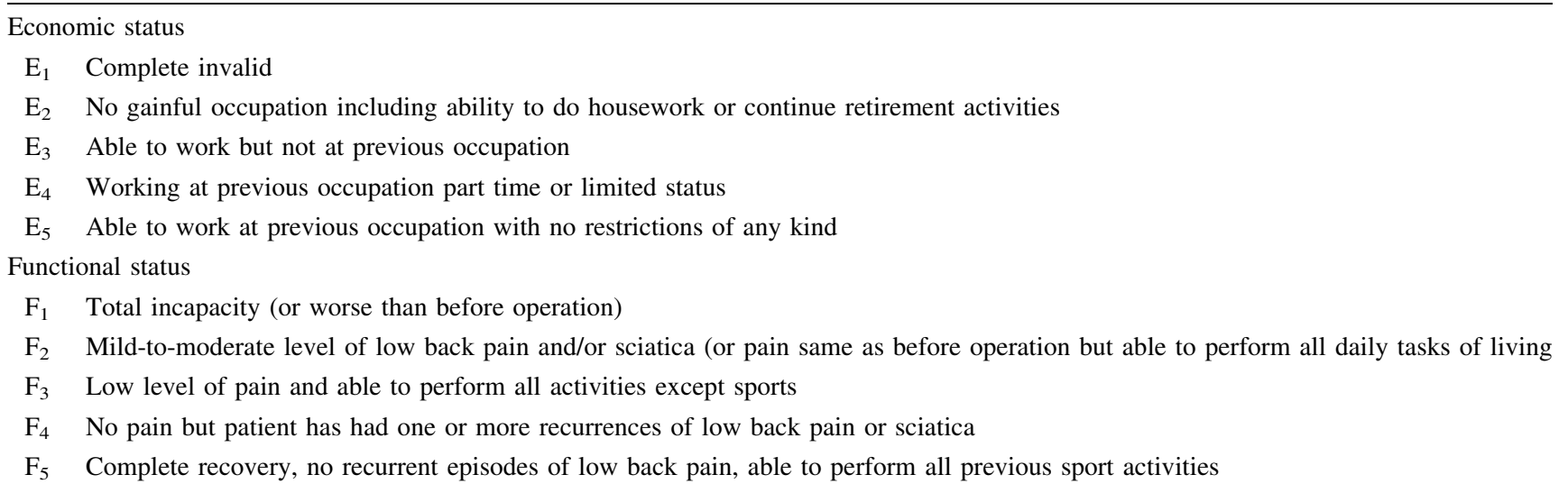


organized results in only three categories: good (8-10 points), moderate (6-7 points) and poor (5 points or less). As a consequence, the threshold values were different for each class, and the cutoff value for poor outcome was different.

In 1994, Davis [8] administered the PS retrospectively and made use of direct evaluation, phone interviews and job agency databases. He examined long-term outcomes of different surgical procedures and compared his results to the study of Pappas. Davis highlighted the dearth of consensus on the meaning and quantification of long-term results, which varied between 4 and 20 years. He asserted that a follow-up longer than 4 years could be considered suitable to detect possible recurrences.

Similarly, retrospective studies were published years later: the purpose of the study of Schoeggl et al. [9] was to measure medium- and long-term surgical outcomes. The PS—as a self-reported questionnaire-was mailed to 672 patients who underwent microdiscectomy surgery between 1990 and 1998. The authors suggested further studies to compare results by making patients, surgeons and independent observers fill out the scale. After comparing their data and the results of other prospective studies, they suggested employing the PS as standardized criteria to evaluate postoperative surgery of the lumbar spine.

Since the end of the 1990s, debate has continued with regard to the most appropriate tool to measure the outcome and for data collection, and different comparison methods have been criticized. For instance, some authors doubted the accuracy and reliability of retrospective reports, in which,

Table 3 The Massachusetts General Hospital Anatomic Economic Functional Rating System [4]

\begin{tabular}{ll}
\hline A0 & Pseudoarthrosis \\
A1 & Unilateral pseudoarthrosis \\
A2 & Insufficient unilateral fusion mass \\
A3 & Contiguous fusion mass without hypertrophy \\
A4 & Solid fusion with hypertrophy \\
E0 & Complete invalid \\
E1 & No gainful occupation \\
E2 & Able to work but did not return to previous occupation \\
E3 & Returned to previous occupation in part-time or limited status \\
E4 & Returned to previous occupation without any restriction of any \\
F0 & Paind \\
F1 Level of LBP is the same as before operation but able to perform \\
all daily tasks of living \\
F2 & Low level of pain and able to perform all activities except sport \\
F3 & No pain but patient has had one or more recurrences of LBP or \\
& sciatica \\
F4 Complete recovery, no recurrent episodes of LBP and able to \\
\end{tabular}

years after surgery, patients are asked to describe the difference between their own condition before and after the operation, overestimating surgical success $[38,39]$.

Other authors stated that it is necessary to make use of a multidimensional set of outcomes to evaluate complex pathologies like the ones affecting the lumbar spine. Among these, Deyo et al. [40] recommended a group of tests for the LBP, which was subsequently used by other authors [41].

In 2000, Berger et al. [10] criticized the indirect evaluation of phone interviews and questionnaires and published a study by using direct evaluation. The authors reported medium- and long-term outcomes (3-4 years) of 1,000 patients who had undergone lumbar surgery and had current work-related law suits. The authors examined subjects clinically with a direct evaluation and with the PS as the only semiquantitative measure of outcome. Data comparison showed a noticeable discrepancy between the low rate of neurological deficits and the considerable number of subjects unemployed because of chronic pain. The authors concluded that psychosocial factors had to be taken into account, and surgical efficacy could not be measured only by evaluating work-related conditions.

In 2002, Blount et al. [42] focused on elaborating standardized and multidimensional tools in order to reduce the risk of subjective bias as much as possible. The authors conducted a review of 27 studies on spinal fusion outcomes by finding the most common tools, and afterward they indicated a set of tools to measure the subsequent variables: general health status, lumbar disability, patient satisfaction, return to previous occupation, medication use and status of anatomical fusion. Especially, they suggested the "economic" version of Schnee [43] with respect to the returnto-work item, because it was the only available tool to quantify this area. In contrast, they did not recommend the Prolo Functional Scale to assess the spinal disability and preferred the ODI to evaluate lumbar outcomes and the Neck Disability Index to evaluate the cervical ones.

Furthermore, discrepancies between anatomical and functional outcomes are stressed by several authors. Porchet et al. [11] compared radiological findings and clinical examination by administering pain and disability scores. Concerning the PS, the correlation was not linear with respect to the others because of the difference between the group with severe disk conditions (sequestrum, extrusion) and the group with moderate disk conditions (bulging, protrusion). The author concluded that "poor" economic and functional levels constituted risk factors for severe disk pathology.

In other studies, controversial correlations were found between the radiological report and surgical success, depending on whether the outcome was obtained according to the patients' perception or the surgeons' criteria $[42,44]$. 
Significant differences were reported between subjective satisfaction (67\%) and clinical success (39\%) [12].

In some cases, researchers chose integrated measures that included both the subjective perception of patients and the clinical ones of surgeons. Among these studies, Voorhies et al. [13] provided three definitions of clinical success related to the VAS, PS and surgeon examination, and Costa et al. [14] used a final cumulative score with the aim of assessing the efficacy of a lumbar fusion device by adding the VAS and PS scores.

Some randomized controlled trials (RCT) of high methodological quality used the PS as the primary outcome measure. In order to assess the efficacy of sequestrectomy as opposed to microdiscectomy, Thomé et al. [15] used the original PS along with the SF-36, VAS and patient satisfaction outcome. Dantas et al. [16] administered the scale to measure the results of two different stabilization techniques along with the Roland and Morris disability questionnaire (RMDQ) and ODI.

In several RCTs, the PS was considered an observational tool to measure post-surgical outcomes. Arts et al. [17] compared the efficacy of two surgical procedures, Peul et al. [18] compared early surgical intervention and prolonged conservative treatment for sciatica, Brox et al. [19, 20] evaluated the efficacy of lumbar fusion and conventional physical therapy vs. cognitive rehabilitation, and finally the recent RCT of Hellum et al. [21] examined the efficacy of a conservative protocol compared to disc replacement in patients with chronic LBP. Hence, in these studies and in many others, the PS was considered as a secondary outcome, whereas commonly the main ones were self-reported questionnaires that have been validated in several languages.

\section{Modified versions of the Prolo Scale}

In 1997, the PS was modified by Schnee et al. [43], who administered a self-reported version of the scale to 52 patients who underwent lumbar fusion.

As reported in Table 4, non-relevant changes in the economic subscale were introduced so as to provide a more explicit correlation with daily activities, not necessarily work-related. The most evident change referred to the functional subscale instead, where items F3, 4 and 5 were simplified, and they emphasized the frequency and intensity of pain.

In particular, the original PS considered the score of the F3 item as low pain, which allows for daily activities but not sports, whereas the F4 item indicates absence of pain but recent recurrence of LBP (without any specification concerning the level of bearable activity). Absurdly, a patient with low pain and who is able to perform all activities except sports (E3F3 original scale) could get a lower score than a patient with recent recurrence who would not currently feel pain but is unable to perform certain activities (E3F4 original scale).

This modified version was named the "economic and functional rating scale" and was used by other authors [4549] and recommended by Blount [42] for the economic subscale.

In 2000, Brantigan et al. [50] modified the scale in a multicenter-2-year retrospective randomized trial in which they administered a protocol that was created in the 1990s [51] and approved by the Food and Drug Administration (FDA) in 1999 in order to introduce a surgical device (I/F carbon cage) for posterior lumbar interbody fusion. The authors declined using common tools to assess the LBP (e.g., the ODI, RMDQ, etc.), yet they administered the PS because it was more useful to compare data from surgical studies carried out at different times. Nevertheless, they stated for the first time that the PS had not been validated yet; therefore, they suggested a modified version with 20 items (Table 5). This "modified Prolo Scale" presents, beyond the economic and functional subscales, which were different with respect to the original version, a pain subscale $(\mathrm{P})$ and a medication subscale (M), both with five items. The authors affirmed that the PS already included outcomes of pain, function, economic status and use of pain medication, but in their study each of these parameters was evaluated separately. This difference influenced the final score, which could vary from a minimum of 4 to a maximum of 20 points. In their study, the authors of the

Table 4 The Prolo Economic and Functional Rating Scale (Schnee et al. [43])

\begin{tabular}{lllll}
\hline Economic (activity) status & & & Functional (pain) status \\
\cline { 1 - 2 } Grade & Description & & Grade & Description \\
\hline E1 & Complete invalid (worse) & & F1 & Total incapacity (worse) \\
E2 & No gainful occupation (including housework or retirement activities) & & F2 & Moderate-to-severe daily pain (no change) \\
E3 & Working/active but not at premorbid level & & F3 & Low level of daily pain (improved) \\
E4 & Working/active at previous level w/limitation & & F4 & Occasional or episodic pain \\
E5 & Working/active at previous level w/o restrictions & & F5 & No pain \\
\hline
\end{tabular}


modified Prolo Scale determined the clinical success at 2-year follow-up as excellent (20-17 points), good (16-13 points) and fair (12-9) with a minimal clinical importance difference (MCID) of 3 points. The evaluation was performed before and after surgery at 1-, 3-, 6-, 12- and 24-month follow-ups. The authors matched all criteria developed in 1997 by the FDA and considered pain relief, functional enhancement, and functional neuromuscular improvement as indexes of clinical success. These variables were measured by using both the new 20-point scale and the original 10-point scale. Because calculations of clinical success based on the 10-point Prolo Scale, the 20-point scale, and the FDA clinical success criteria did not differ statistically, results can be meaningfully compared to other studies using the Prolo score, including the clinical studies of different interbody fusion devices.

Because of the sample size, the exact protocol definition and encouraging results, this study was taken as a reference system in the following years by several authors, who chose the modified version [52-58] or only some of its items. For instance, Weber [59] used the "Pain" subscale, Pellisé [39] the "Functional" and "Pain" subscales.

Since the study of Brantigan et al. [50] was carried out, three different versions of the PS have been administered to lumbar surgery patients: the original version, Schnee's modified version and the 20-point one according to Brantigan et al. Another version of the scale, called the "modified Prolo scale," was adapted for the cervical spine (Table 6). It was proposed by Davis in 1996 [60] to measure long-term outcomes after posterior decompression for cervical radiculopathy and was administered in a retrospective study.

The PS modified by Davis is mentioned in retrospective [61] and prospective studies [62] and RCTs [63, 64], and its use was recommended (with B strength) in the diagnosis and treatment of cervical radiculopathy "from degenerative disorders guidelines" (North American Spine Society, [65]).

Several studies we examined did not specify the exact version of the PS they adopted. As a consequence, researchers who did not know the whole evolution of the scale could have some difficulty understanding which version of this scale was used or might try to obtain that information from other parts of the article. Confusion increased when the authors described the scale they administered as "modified" although they had used the original version. Among these, Dreyzin and Esses [22] applied the evaluation system retrospectively to 20 patients treated for spondylolisthesis and spondylolysis with the aim of compared the efficacy of two different surgical procedures. The PS was administered only postoperatively by asking patients to evaluate surgical outcome. The authors probably only defined this version as the "modified Prolo Scale" because there were merely negligible differences in how to write the items (e.g., grade 1 vs. E1, etc.).

Conversely, other versions of the "modified Prolo Scale" were significantly different from the original one. For instance, Kuslich and colleagues [66] used a 6-point instead of a 5-point scale to assess lumbar pain. Furthermore, Kuslich used a thoroughly opposite rating system from Prolo: 1 point meant no pain and 6 points disabling pain, whereas Prolo considered 1 as poor outcome. The economic status was measured without providing any details on the load or activity type and only the percentage of patients that returned to work was reported.

Despite its differences from the original scale, Ohnmeiss and Guyer [67] mentioned the study of Kuslich in their review aiming to verify the most adequate follow-up time after surgery of spinal implant devices. In this study it was

Table 5 Clinical evaluation scales_-'modified Prolo scale' (Brantigan et al. [51])

\begin{tabular}{|c|c|c|c|c|c|c|c|}
\hline \multicolumn{2}{|c|}{ Pain } & \multicolumn{2}{|c|}{ Function } & \multicolumn{2}{|c|}{ Economic } & \multicolumn{2}{|c|}{ Medication } \\
\hline P1 & $\begin{array}{l}\text { Excruciating } \\
\text { or } \\
\text { unbearable } \\
\text { pain }\end{array}$ & F1 & Total incapacity & E1 & $\begin{array}{l}\text { Unable to do tasks } \\
\text { around the home }\end{array}$ & M1 & $\begin{array}{l}10 \text { or more hydrocodone tablets or } \\
\text { equivalent }\end{array}$ \\
\hline P2 & Severe pain & $\mathrm{F} 2$ & Able to do activities in the home & E2 & $\begin{array}{l}\text { Able to do tasks } \\
\text { around the home but } \\
\text { unable to work }\end{array}$ & M2 & $6-9$ hydrocodone tablets or equivalent \\
\hline P3 & Moderate pain & F3 & $\begin{array}{l}\text { Able to do activities outside the home } \\
\text { with limitation of moderate-demand } \\
\text { activities }\end{array}$ & E3 & $\begin{array}{l}\text { Able to work at light } \\
\text { or sedentary } \\
\text { capacity }\end{array}$ & M3 & $3-5$ hydrocodone tablets or equivalent \\
\hline P4 & Mild pain & $\mathrm{F} 4$ & $\begin{array}{l}\text { Limitation of strenuous activities or } \\
\text { sports }\end{array}$ & E4 & $\begin{array}{l}\text { Able to work at } \\
\text { moderate capacity }\end{array}$ & M4 & $\begin{array}{l}\text { Regular nonsteroidal anti- } \\
\text { inflammatory drugs (NSAIDs) and/ } \\
\text { or occasional hydrocodone tablets }\end{array}$ \\
\hline P5 & No pain & F5 & Able to do all activities & E5 & $\begin{array}{l}\text { Able to work at heavy } \\
\text { capacity or previous } \\
\text { occupation }\end{array}$ & M5 & $\begin{array}{l}\text { None or occasional NSAID or } \\
\text { equivalent }\end{array}$ \\
\hline
\end{tabular}


mentioned that Kuslich administered the "modified Prolo Scale" and Brantigan the "5-point Likert Scale for pain" instead.

\section{Psychometric properties of the Prolo Scale}

In 1997, Woertgen et al. [23] administered the PS in a prospective study on 121 patients affected by lumbar hernia who underwent surgery, comparing this scale with another lumbar disability scale (the low back outcome score-LBOS). Four different instruments were administered: the LBOS, PS, pain grading scale and quality of life scale. The authors highlighted that data collected with the PS and LBOS were not statistically different; nevertheless,

Table 6 The Prolo Functional and Economic Outcome Rating Scale modified for postoperative cervical radiculopathy (Davis [60])

\begin{tabular}{|c|c|}
\hline Score & Criteria \\
\hline \multicolumn{2}{|c|}{ Economic status } \\
\hline 1 & Complete invalid \\
\hline 2 & $\begin{array}{l}\text { No gainful occupation, including ability to do housework, } \\
\text { school or retirement activities }\end{array}$ \\
\hline 3 & $\begin{array}{l}\text { Ability to work, but not at previous occupation: able to } \\
\text { perform housework, school and retirement activities }\end{array}$ \\
\hline 4 & $\begin{array}{l}\text { Working at previous occupation part-time or with limited } \\
\text { status }\end{array}$ \\
\hline 5 & Able to work at previous occupation with no restrictions \\
\hline \multicolumn{2}{|c|}{ Functional (social) status } \\
\hline 1 & Total incapacity (worse than prior to operation) \\
\hline 2 & $\begin{array}{l}\text { Persistent neck and arm pain, persistent paresthesias, motor } \\
\text { weakness same as prior to operation (able to perform tasks } \\
\text { of daily living) }\end{array}$ \\
\hline 3 & $\begin{array}{l}\text { Moderate neck and arm pain, persistent paresthesias, minimal } \\
\text { motor weakness }\end{array}$ \\
\hline 4 & $\begin{array}{l}\text { No neck or arm pain, persistent paresthesias in fingers, no } \\
\text { motor weakness }\end{array}$ \\
\hline 5 & $\begin{array}{l}\text { No neck or arm pain, no paresthesias, no motor weakness, } \\
\text { complete recovery, able to perform previous sports } \\
\text { activities }\end{array}$ \\
\hline
\end{tabular}

according to the scale in use, different prognostic factors could lead to different outcome measures. Some factors (postoperative duration of pain and duration of preoperative paresis) would affect the final outcome of all scales, while other factors would be specific only to one measure. In particular, according to the PS a positive SLR test before $30^{\circ}$ and the ability to walk for $500 \mathrm{~m}$ would be predictive factors of poor outcome.

In 2002 Porchet et al. [11] conducted a cohort study on 394 patients with sciatica to verify the relationship between the clinical examination (measured on the RMDQ, SF-36, VAS and PS) and the radiological assessment according to Modic criteria. A significant inverse association $(P<0.001)$ was found between low levels of PS and high severity of disc disease, but the assumption of a linear correlation was rejected by statistical testing $(P=0.064)$. The authors reported that "having a poor functional status on PS $(<5)$ represented a threefold risk of severe disc disease $\quad(\mathrm{OR}=2.91 ; \quad 95 \% \quad$ confidence interval 1.74-4.87)," so the Prolo score was retained in the multivariate logistic model as an independent predictor of severe disc disease. In this study, the PS was used as a disability score and not as a tool to assess surgical outcome, as it was intended by the original researchers in 1986.

In 2007, Voorhies et al. [13] carried out a study that might be considered a validation study of PS. It was a nonrandomized trial that investigated the surgical outcome of 110 sciatica patients by adopting a six-measure set (VAS, McGill Sensory/Affective Scores, Prolo Economic/Functional Scores, Modified Ransford Pain Drawing Score). The purpose of the study was to elaborate an outcomepredictive model to determine whether a score is able to predict clinical success. The authors took into account three ways to define "clinical success": surgeon evaluation, $50 \%$ or greater reduction in the VAS score, and combined PS score at the excellent level (8-10 points). The latter was reported as a 10-point version with little difference with respect to the original paper, but more understandable and easier to compile (Table 7).

Table 7 The modified Prolo economic and functional scores [13]

\begin{tabular}{lc}
\hline Prolo economic score (modified) & Prolo functional score (modified) \\
\hline Complete invalid (confined to the home) & $\begin{array}{c}\text { Severe pain (cannot do anything, somebody has to help you day } \\
\text { to day) } \\
\text { Moderate level of pain (able to take care of yourself without } \\
\text { help, but can't do anything else) }\end{array}$ \\
$\begin{array}{l}\text { No gainful occupation (including no housework and no retirement or leisure } \\
\text { activities) }\end{array}$ & $\begin{array}{c}\text { Low level of pain (able to do everything except sports, } \\
\text { physically demanding leisure activities or heavy housework) } \\
\text { hble to work but not at your previous job (nor do the same types of } \\
\text { horking at previous job but on a part-time or light duty status (same kind of } \\
\text { housework or retirement activities as before, but reduced in the amount of } \\
\text { time and effort) }\end{array}$ \\
$\begin{array}{c}\text { Able to work at previous job (or do other things) with no restrictions of any } \\
\text { kind }\end{array}$ & $\begin{array}{c}\text { Complete recovery, no pain, able to perform previous sport } \\
\text { activities }\end{array}$ \\
\hline
\end{tabular}


Table 8 Significance tests [13]: comparison of each outcome measure between pre- and postoperative status

\begin{tabular}{lcccc}
\hline Variable & $N$ & Preoperative & Postoperative & $P$ value \\
\hline $\begin{array}{l}\text { Prolo economic } \\
\text { score }\end{array}$ & 110 & $2.78 \pm 1.24$ & $3.65 \pm 1.16$ & $<0.001$ \\
$\begin{array}{l}\text { Prolo functional } \\
\quad \text { score }\end{array}$ & 110 & $2.04 \pm 0.65$ & $3.41 \pm 1.02$ & $<0.001$ \\
$\begin{array}{l}\text { McGill sensory score } \\
\text { McGill affective }\end{array}$ & 110 & $13.00 \pm 7.42$ & $5.56 \pm 6.65$ & $<0.001$ \\
$\quad$ score & 110 & $3.30 \pm 3.70$ & $1.53 \pm 2.77$ & $<0.001$ \\
$\begin{array}{l}\text { Visual analog scale } \\
\quad \text { VAS) }\end{array}$ & 110 & $7.36 \pm 1.94$ & $3.21 \pm 2.72$ & $<0.001$ \\
$\begin{array}{l}\text { Modified Ransford Pain } \\
\text { Drawing Score [from }\end{array}$ & 110 & $1.30 \pm 1.42$ & $0.64 \pm 1.25$ & $<0.004$ \\
$\quad$ Voorhies] (MRS) & & & & \\
\hline
\end{tabular}

The authors found statistically significant differences between pre- and postoperative data for all outcome measures $(P<0.001$ for PS-see Table 8$)$, confirming their sensitivity. Moreover, correlation between scores and comorbidity factors (preoperative pain, legal and psychiatric factors) was investigated, and it was shown that those factors strongly influenced the outcome prediction. However, the lack of indicators of reliability, repeatability and validity (criterion, content and construct) led us to conclude that PS has never been examined from the psychometrical point of view.

Nevertheless, some authors who referred to the existence of validation studies of the PS neither mentioned the study of Voorhies nor provided any references to support their statements.

As previously mentioned, in the study of Debusscher and Troussel [25] it was affirmed that the Prolo score modified by Dreyzin and Esses, VAS and ODI "are scientifically validated for assessment of LBP." Furthermore, in 2010 Brotis et al. [34] stated that the PS had been standardized and validated in Greece, but only mentioned the studies of Blount [42] and Prolo [1]. Finally, in 2007 Alrawi and colleagues [62] used the Davis modified version to examine the surgical outcome of cervical radiculopathy, and they stated that clinical evaluation was carried out by means of a validated scoring systems (the Prolo functional and economic system).

\section{Discussion}

To date, there is insufficient consensus about the most adequate and reliable tool to measure lumbar surgical outcomes, and this prevents the comparison of the results among different clinical studies. In order to investigate such a complex condition as lumbar pathology, there is large consensus among authors as to the need to adopt a multidimensional set of measures that also allows considering comorbidity factors and reduces subjective bias.

The PS has been adopted for several years because it is easy to administer and useful for comparing a significant amount of data from surgical studies carried out at different times. Even though Voorhies [13] and Woertgen [23] demonstrated the scale sensitivity among a battery of tests, no thorough validation study was found in the current literature.

The original ten-point scale is widely used; however, the presence of two modified versions $[43,50]$ and the unclear indications given by authors can easily lead to mistakes by those who do not thoroughly know the evolution of the scale. Hence, in future studies, we strongly suggest specifying the version in use. In recent studies, PS has usually been considered a secondary outcome, whereas the primary measures consisted of validated specific tools based on patient perception (the ODI, RMDQ, SF-36).

Nonetheless, among the studies that used a validated scoring system, there is a lack of consensus about what clinical success means, as the study of Tafazal and Sell showed [68]. The authors stated that the outcome measured by means of three different scales (the ODI, LBOS, VAS), in order to achieve a good or excellent outcome, varies depending on the surgical procedure. In fact, data confirmed that the minimum clinically important difference (MCID) obtained for discectomy surgery is higher than the one for decompression or fusion surgery. This article shows that a single scoring method to assess postoperative outcome could be considered insufficient regardless of surgical technique.

In the current literature, the presence of new multidimensional tools such as the Core Outcome Measures Index $[69,70]$ to assess the LBP and the minimum core outcome set [71] for lumbar surgical outcome leads us to state that the issue concerning the lack of homogeneity in outcome measures still exists.

We suggest that future studies specify the exact version of the scale they used and thoroughly investigate the psychometric properties (reliability, validity and responsiveness) of questionnaires employed to evaluate the results of spinal surgery.

\section{Conflict of interest None.}

Open Access This article is distributed under the terms of the Creative Commons Attribution License which permits any use, distribution, and reproduction in any medium, provided the original author(s) and the source are credited.

\section{References}

1. Prolo DJ, Oklund SA, Butcher M (1986) Toward uniformity in evaluating results of lumbar spine operations. A paradigm applied to posterior lumbar interbody fusions. Spine 11:601-606 
2. Odom GL, Finney W, Woodhall B (1958) Cervical disk lesions. J Am Med Assoc 166:23-28

3. Macnab I (1971) Negative disc exploration. An analysis of the causes of nerve-root involvement in sixty-eight patients. J Bone Joint Surg Am 53:891-903

4. Dawson EG, Lotysch M 3rd, Urist MR (1981) Intertransverse process lumbar arthrodesis with autogenous bone graft. Clin Orthop Relat Res 154:90-96

5. Kennedy Robert H (1931) Fracture of the shaft of both bones of the leg: an analysis of 107 cases. Ann Surg 93:563-586

6. Urist MR (1956) Orthopaedic surgery in World War II in the European theatre of operations. US Army Medical Department. http://history.amedd.army.mil/booksdocs/wwii/orthoeuropn/chapter 19.htm Accessed 15 November 2012

7. Pappas CT, Harrington T, Sonntag VK (1992) Outcome analysis in 654 surgically treated lumbar disc herniations. Neurosurgery 30:862-866

8. Davis RA (1994) A long-term outcome analysis of 984 surgically treated herniated lumbar discs. J Neurosurg 80:415-421

9. Schoeggl A, Reddy M, Matula C (2003) Functional and economic outcome following microdiscectomy for lumbar disc herniation in 672 patients. J Spinal Disord Tech 16:150-155

10. Berger E (2000) Late postoperative results in 1000 work related lumbar spine conditions. Surg Neurol 54:101-106

11. Porchet F, Wietlisbach V, Burnand B, Daeppen K, Villemure JG, Vader JP (2002) Relationship between severity of lumbar disc disease and disability scores in sciatica patients. Neurosurgery 50:1253-1259

12. Agazzi S, Reverdin A, May D (1999) Posterior lumbar interbody fusion with cages: an independent review of 71 cases. J Neurosurg 91:186-192

13. Voorhies RM, Jiang X, Thomas N (2007) Predicting outcome in the surgical treatment of lumbar radiculopathy using the pain drawing score, McGill short form pain questionnaire, and risk factors including psychosocial issues and axial joint pain. Spine J 7:516-524

14. Costa F, Sassi M, Ortolina A et al (2011) Stand-alone cage for posterior lumbar interbody fusion in the treatment of high-degree degenerative disc disease: design of a new device for an "old" technique. A prospective study on a series of 116 patients. Eur Spine J 20:S46-S56

15. Thomé C, Barth M, Scharf J, Schmiedek P (2005) Outcome after lumbar sequestrectomy compared with microdiscectomy: a prospective randomized study. J Neurosurg Spine 2:271-278

16. Dantas FL, Prandini MN, Ferreira MA (2007) Comparison between posterior lumbar fusion with pedicle screws and posterior lumbar interbody fusion with pedicle screws in adult spondylolisthesis. Arq Neuropsiquiatr 65:764-770

17. Arts MP, Peul WC, Brand R, Koes BW, Thomeer RT (2006) Cost-effectiveness of microendoscopic discectomy versus conventional open discectomy in the treatment of lumbar disc herniation: a prospective randomized controlled trial. BMC Musculoskelet Disord 13(7):42

18. Peul WC, van den Hout WB, Brand R, Thomeer RT, Koes BW, Leiden-The Hague Spine Intervention Prognostic Study Group (2008) Prolonged conservative care versus early surgery in patients with sciatica caused by lumbar disc herniation: two year results of a randomized controlled trial. BMJ 336:1355-1358

19. Brox JI, Sørensen R, Friis A et al (2003) Randomized clinical trial of lumbar instrumented fusion and cognitive intervention and exercises in patients with chronic low back pain and disc degeneration. Spine 28:1913-1921

20. Brox JI, Reikerås O, Nygaard $\varnothing$ et al (2006) Lumbar instrumented fusion compared with cognitive intervention and exercises in patients with chronic back pain after previous surgery for disc herniation: a prospective randomized controlled study. Pain 122:145-155

21. Hellum C, Johnsen LG, Storheim K et al (2011) Surgery with disc prosthesis versus rehabilitation in patients with low back pain and degenerative disc: two year follow-up of randomised study. BMJ 19:d2786

22. Dreyzin V, Esses SI (1994) A comparative analysis of spondylolysis repair. Spine 19:1909-1914

23. Woertgen C, Holzschuh M, Rothoerl RD, Brawanski A (1997) Does the choice of outcome scale influence prognostic factors for lumbar disc surgery? A prospective, consecutive study of 121 patients. Eur Spine J 6:173-180

24. Jolles BM, Porchet F, Theumann N (2001) Surgical treatment of lumbar spinal stenosis. Five-year follow-up. J Bone Joint Surg Br 83:949-953

25. Debusscher F, Troussel S (2007) Direct repair of defects in lumbar spondylolysis with a new pedicle screw hook fixation: clinical, functional and Ct-assessed study. Eur Spine $\mathbf{J}$ 16:1650-1658

26. Ahn Y, Lee SH, Lee JH, Kim JU, Liu WC (2009) Transforaminal percutaneous endoscopic lumbar discectomy for upper lumbar disc herniation: clinical outcome, prognostic factors, and technical consideration. Acta Neurochir (Wien) 151:199-206

27. Vaga S, Brayda-Bruno M, Perona F et al (2009) Molecular MR imaging for the evaluation of the effect of dynamic stabilization on lumbar intervertebral discs. Eur Spine J 18:40-48

28. Mascarenhas AA, Thomas I, Sharma G, Cherian JJ (2009) Clinical and radiological instability following standard fenestration discectomy. Indian J Orthop 43:347-351

29. Moon BJ, Cho BY, Choi EY, Zhang HY (2009) Polymethylmethacrylate-augmented screw fixation for stabilization of the osteoporotic spine: a three-year follow-up of 37 patients. J Korean Neurosurg Soc 46:305-311

30. Kim DH, Jeong ST, Lee SS (2009) Posterior lumbar interbody fusion using a unilateral single cage and a local morselized bone graft in the degenerative lumbar spine. Clin Orthop Surg $1: 214-221$

31. Assietti R, Morosi M, Block JE (2010) Intradiscal electrothermal therapy for symptomatic internal disc disruption: 24-month results and predictors of clinical success. J Neurosurg Spine $12: 320-326$

32. Dalgic A, Uckun O, Ergungor MF et al (2010) Comparison of unilateral hemilaminotomy and bilateral hemilaminotomy according to dural sac area in lumbar spinal stenosis. Minim Invasive Neurosurg 53:60-64

33. Selviaridis P, Foroglou N, Tsitlakidis A, Hatzisotiriou A, Magras I, Patsalas I (2010) Long-term outcome after implantation of prosthetic disc nucleus device (PDN) in lumbar disc disease. Hippokratia 14:176-184

34. Brotis AG, Paterakis KN, Tsiamalou PM, Fountas KN, Hahjigeorgiou GM, Karavelis A (2010) Instrumented posterior lumbar fusion outcomes for lumbar degenerative disorders in a southern European, semirural population. J Spinal Disord Tech 23:444-450

35. Schnee CL, Ansell LV (1997) Selection criteria and outcome of operative approaches for thoracolumbar burst fractures with and without neurological deficit. J Neurosurg 86:48-55

36. Stancić MF, Gregorović E, Nozica E, Penezić L (2001) Anterior decompression and fixation versus posterior reposition and semirigid fixation in the treatment of unstable burst thoracolumbar fracture: prospective clinical trial. Croat Med J 42:49-53

37. Perez-Cruet MJ, Kim BS, Sandhu F, Samartzis D, Fessler RG (2004) Thoracic microendoscopic discectomy. J Neurosurg Spine 1:58-63

38. Turner JA, Ersek M, Herron L et al (1992) Patient outcomes after lumbar spinal fusions. JAMA 268:907-911 
39. Pellisé F, Vidal X, Hernández A, Cedraschi C, Bagó J, Villanueva C (2005) Reliability of retrospective clinical data to evaluate the effectiveness of lumbar fusion in chronic low back pain. Spine 30:365-368

40. Deyo RA, Battie M, Beurskens AJ et al (1998) Outcome measures for low back pain research. A proposal for standardized use. Spine 23:2003-2013

41. Bombardier C (2000) Outcome assessments in the evaluation of treatment of spinal disorders: summary and general recommendations. Spine 25:3100-3103

42. Blount KJ, Krompinger WJ, Maljanian R, Browner BD (2002) Moving toward a standard for spinal fusion outcomes assessment. J Spinal Disord Tech 15:16-23

43. Schnee CL, Freese A, Ansell LV (1997) Outcome analysis for adults with spondylolisthesis treated with posterolateral fusion and transpedicular screw fixation. J Neurosurg 86:56-63

44. Howe J, Frymoyer JW (1985) The effects of questionnaire design on the determination of end results in lumbar spinal surgery. Spine 10:804-805

45. La Rosa G, Cacciola F, Conti A et al (2001) Posterior fusion compared with posterior interbody fusion in segmental spinal fixation for adult spondylolisthesis. Neurosurg Focus 10:E9

46. Kristof RA, Aliashkevich AF, Schuster M, Meyer B, Urbach H, Schramm J (2002) Degenerative lumbar spondylolisthesisinduced radicular compression: nonfusion-related decompression in selected patients without hypermobility on flexion-extension radiographs. J Neurosurg 97:281-286

47. Neen D, Noyes D, Shaw M, Gwilym S, Fairlie N, Birch N (2006) Healos and bone marrow aspirate used for lumbar spine fusion: a case controlled study comparing healos with autograft. Spine 31:E636-E640

48. Würgler-Hauri CC, Kalbarczyk A, Wiesli M, Landolt H, Fandino J (2008) Dynamic neutralization of the lumbar spine after microsurgical decompression in acquired lumbar spinal stenosis and segmental instability. Spine 33:E66-E72

49. Kotil K, Akçetin M, Tari R, Ton T, Bilge T (2009) Replacement of vertebral lamina (laminoplasty) in surgery for lumbar isthmic spondylolisthesis. A prospective clinical study. Turk Neurosurg 19:113-120

50. Brantigan JW, Steffee AD, Lewis ML, Quinn LM, Persenaire JM (2000) Lumbar interbody fusion using the Brantigan I/F cage for posterior lumbar interbody fusion and the variable pedicle screw placement system: two-year results from a food and drug administration investigational device exemption clinical trial. Spine 25:1437-1446

51. Brantigan JW, Steffee AD (1993) A carbon fiber implant to aid interbody lumbar fusion. Two-year clinical results in the first 26 patients. Spine 18:2106-2107

52. Salehi SA, Tawk R, Ganju A, LaMarca F, Liu JC, Ondra SL (2004) Transforaminal lumbar interbody fusion: surgical technique and results in 24 patients. Neurosurgery 54:368-374

53. Mummaneni PV, Pan J, Haid RW, Rodts GE (2004) Contribution of recombinant human bone morphogenetic protein-2 to the rapid creation of interbody fusion when used in transforaminal lumbar interbody fusion: a preliminary report. J Neurosurg Spine 1:19-23

54. Beringer WF, Mobasser JP (2006) Unilateral pedicle screw instrumentation for minimally invasive transforaminal lumbar interbody fusion. Neurosurg Focus 20:E4

55. Fogel GR, Toohey JS, Neidre A, Brantigan JW (2006) Outcomes of L1-L2 posterior lumbar interbody fusion with the lumbar I/F cage and the variable screw placement system: reporting unexpected poor fusion results at L1-L2. Spine J 6:421-427

56. Yang BP, Ondra SL, Chen LA, Jung HS, Koski TR, Salehi SA (2006) Clinical and radiographic outcomes of thoracic and lumbar pedicle subtraction osteotomy for fixed sagittal imbalance. J Neurosurg Spine 5:9-17

57. Dhall SS, Wang MY, Mummaneni PV (2008) Clinical and radiographic comparison of mini-open transforaminal lumbar interbody fusion with open transforaminal lumbar interbody fusion in 42 patients with long-term follow-up. J Neurosurg Spine 9:560-565

58. Xiao Y, Li F, Chen Q (2010) Transforaminal lumbar interbody fusion with one cage and excised local bone. Arch Orthop Trauma Surg 130:591-597

59. Weber J, Schönfeld C, Spring A (2009) Sports after surgical treatment of a herniated lumbar disc: a prospective observational study. Z Orthop Unfall 147:588-592

60. Davis RA (1996) A long-term outcome study of 170 surgically treated patients with compressive cervical radiculopathy. Surg Neurol 46:523-530

61. Vitzthum HE, Dalitz K (2007) Analysis of five specific scores for cervical spondylogenic myelopathy. Eur Spine J 16:2096-2103

62. Alrawi MF, Khalil NM, Mitchell P, Hughes SP (2007) The value of neurophysiological and imaging studies in predicting outcome in the surgical treatment of cervical radiculopathy. Eur Spine J 16:495-500

63. Cho DY, Lee WY, Sheu PC (2004) Treatment of multilevel cervical fusion with cages. Surg Neurol 62:378-385

64. Feiz-Erfan I, Harrigan M, Sonntag VK, Harrington TR (2007) Effect of autologous platelet gel on early and late graft fusion in anterior cervical spine surgery. J Neurosurg Spine 7:496-502

65. Bono CM, Ghiselli G, Gilbert TJ, Kreiner DS, Reitman C, Summers JT, Baisden JL, Easa J, Fernand R, Lamer T, Matz PG, Mazanec DJ, Resnick DK, Shaffer WO, Sharma AK, Timmons RB, Toton JF, North American Spine Society (2011) An evidence-based clinical guideline for the diagnosis and treatment of cervical radiculopathy from degenerative disorders. Spine J 11(1):64-72. doi:10.1016/j.spinee.2010.10.023

66. Kuslich SD, Danielson G, Dowdle JD et al (2000) Four-year follow-up results of lumbar spine arthrodesis using the Bagby and Kuslich lumbar fusion cage. Spine 25:2656-2662

67. Ohnmeiss D, Guyer MD (2009) Twenty-four month follow-up for reporting results of spinal implant studies: is the guideline supported by the literature? SAS J 3:100-107

68. Tafazal SI, Sell PJ (2006) Outcome scores in spinal surgery quantified: excellent, good, fair and poor in terms of patientcompleted tools. Eur Spine J 15:1653-1660

69. Mannion AF, Porchet F, Kleinstuick FS et al (2009) The quality of spine surgery from the patient's perspective. Part I: the core outcome measures index in clinical practice. Eur Spine $\mathrm{J}$ $18: 367-373$

70. Genevay S, Cedraschi C, Marty M et al (2012) Reliability and validity of the cross-culturally adapted French version of the core outcome measure index (COMI) in patients with low back pain. Eur Spine 21:130-137

71. Ferrer M, Pellisé F, Escudero O, Alvarez L, Pont A, Alonso J, Deyo R (2006) Validation of a minimum outcome core set in the evaluation of patients with back pain. Spine 31:1372-1379 